\section{Simple and flexible SAS and SPSS programs for analyzing lag-sequential categorical data}

\author{
BRIAN P. O'CONNOR \\ Lakehead University, Thunder Bay, Ontario, Canada
}

This paper describes simple and flexible programs for analyzing lag-sequential categorical data, using SAS and SPSS. The programs read a stream of codes and produce a variety of lag-sequential statistics, including transitional frequencies, expected transitional frequencies, transitional probabilities, adjusted residuals, $z$ values, Yule's Q values, likelihood ratio tests of stationarity across time and homogeneity across groups or segments, transformed kappas for unidirectional dependence, bidirectional dependence, parallel and nonparallel dominance, and significance levels based on both parametric and randomization tests.

Can recurring patterns be identified in sequences of behaviors? This question is a fundamental concern for social scientists who believe that there is order in the behaviors that are displayed and exchanged by individuals. Indeed, the absence of sequential patterns is randomness (Wampold, 1995, p. 194). It is, therefore, ironic and perplexing that the most popular statistical software packages that are used by social scientists (e.g., SPSS and SAS) do not have procedures for identifying sequential patterns.

The questions that can be asked of sequential data are both simple and important. Does one particular behavior tend to follow another particular behavior at rates that are significantly greater than or less than chance? Is one behavior activated by, or inhibited by, the occurrence of other behaviors? In situations where particular behaviors do not immediately follow each other, might they nevertheless still follow one another after several intervening events (lags)? The lack of familiar, simple, and readily available software for answering such questions has probably led many researchers to focus on global judgments and base rates, rather than on behavioral sequences. This is unfortunate, because the neglect of patterns can result in misleading portrayals of the phenomena of interest. For example, Margolin and Wampold (1981) found that distressed and nondistressed couples did not statistically differ in their overall frequencies of negative behaviors. However, the couples did differ in how they used their negative behaviors. Distressed couples displayed more reciprocation of each other's negative behavior, producing more intense exchanges, in comparison with the relatively scattered negative behaviors displayed by nondistressed couples. What distinguishes distressed and

Correspondence concerning this article should be addressed to B. P. O'Connor, Department of Psychology, Lakehead University, 955 Oliver Road, Thunder Bay, ON P7B 5E1, Canada (e-mail: brian. oconnor@lakeheadu.ca). nondistressed couples, according to this research, is not the simple occurrence of negative behaviors, but the patterns in the negative behaviors.

Sequential analyses have been used in research on a variety of issues, including animal behavior (e.g., courtship behavior in the three-spined stickleback), parentinfant interactions, therapist -client interactions, child language, and domestic violence (Bakeman \& Gottman, 1997; Cordova, Jacobson, Gottman, Rushe, \& Cox, 1993; Holloway, Freund, Gardner, Nelson, \& Walker, 1989; Wampold, 1992, 1995). The analytic techniques have been evolving, and they now permit researchers to conduct relatively sophisticated tests of their theories. For example, many theories specify that not only does Person A's behavior affect Person B's behavior, but that Person B's behavior, in turn, feeds back to influence Person A's behavior (Kiesler, 1996; Roloff \& Miller, 1987). Modern sequential analytic techniques permit researchers to examine these circuits and systems in the behaviors that are exchanged between individuals (Wampold, 1992, 1995). Holloway et al. (1989) examined interactions between psychotherapy trainees and their supervisors and found evidence for such a circuit: Advice provided by supervisors tended to be followed by concessions on the part of trainees, and concessions by trainees prompted advice from supervisors. Bidirectional sequential tests permitted the researchers to test both transitions simultaneously, in contrast with traditional unidirectional sequential tests that focus solely on the occurrence of one kind of transition at a time.

Some theorists claim that, although patterns may exist in sequences of social behavior, the nature and degree of the reciprocation that takes place is often not equal or symmetrical. Particular individuals may be sequentially dominant in their interactions with others. For example, therapist dominance occurs when client behaviors are more predictable from therapist behaviors than are therapist behaviors from client behaviors. This pattern may not be desirable in all forms of psychotherapy (e.g., clientcentered therapy), and sequential statistics can be used to identify these tendencies. Some theories even state that people can display superiority in controlling another person's responses while acting submissive. For example, depressed people are believed to exert a strong pull on others to display sympathetic, parental type behavior (Coyne, Burchill, \& Stiles, 1991; Kiesler, 1996), which has the effect of making their significant others feel annoyed and pushed around by someone who is seemingly passive. Sequential tests of parallel and nonparallel dominance permit statistical evaluations of these kinds of theoretically predicted patterns (Wampold, 1984, 1992, 1995). Researchers may also wish to derive estimates of the degrees to which various patterns exist for different individuals or groups and then examine associations between these estimates and external variables, such as per- 
sonality and demographic characteristics or ratings of therapeutic alliance (Wampold \& Kim, 1989). Researchers may also be interested in the degrees to which interventions succeed in altering the maladaptive patterns that characterize psychotherapy clients (Holloway, Wampold, \& Nelson, 1990). Sequential statistics computed for each person are the dependent variables in these kind of analyses and are often more meaningful than global judgments assessed by questionnaires.

Currently, researchers wishing to conduct sequential analyses must acquire additional software programs, learn the often unfamiliar languages of the programs, translate their data into a format that can be processed by the programs, and then translate the results back into their familiar software languages for any further processing. These time-consuming detours are not necessary, because the analyses can be conducted without leaving familiar computing environments. This paper describes relatively simple, efficient, and flexible SAS and SPSS programs for computing a variety of sequential analysis statistics.

Sequential data may be obtained with a variety of recording schemes (Bakeman \& Quera, 1995a). The obtained codes may represent specific events or the occurrence or nonoccurrence of events in successive, timed intervals. Information may also be available for the onset and offset times of a series of behaviors. The present programs permit analyses of any kind of sequential categorical data (events or intervals) in which the duration of the events is not important. Researchers who wish to analyze the durations of their coded events are referred to the programs described by Bakeman and Quera (1995a) and Gardner (1990).

The computations for analyzing sequential categorical data are easily performed with matrix processing procedures (MATRIX-END MATRIX in SPSS, and PROC IML in SAS). The most important step is the construction of a transitional frequency matrix, the cells of which are counts of various antecedent-consequent sequences in a stream of codes. SPSS commands for producing a transitional frequency matrix can be found in Table 1. The data are assumed to be a series of integer codes, with values ranging from " 1 " to whatever value the user specifies in the "number of codes" computation at the start of the program. The semicolons after each integer in the "compute data" command create a one-column data matrix that is then entered into a simple loop that generates a transitional frequency matrix. Another compute statement permits users to specify the desired lag for their analyses. Also in Table 1 are commands that transform and save the transitional frequency matrix for entry into the kinds of SPSS and SAS statistical procedures (e.g., LOGLINEAR, CATMOD) that have been described and recommended in numerous recent papers (e.g., Bakeman, Adamson, \& Strisik, 1995; Bakeman \& Gottman, 1997; Bakeman \& Quera, 1995b; Gottman \& Roy, 1990).
It is also possible to compute a variety of sequential statistics without leaving the matrix processing environment. The addition of a few more command lines to the program in Table 1 permits users to obtain a number of sequential statistics for each cell in their transitional frequency matrices. A series of brief SAS and SPSS programs have been written for these purposes and are described below. The programs run on both mainframe and PC versions of SPSS and SAS. They simply require that the MATRIX-END MATRIX (for SPSS) and PROC IML (for SAS) procedures be available, and these procedures are a standard part of most software packages.

SEQUENTIAL. This program reads a column matrix of data and then computes and displays a square output matrix (the cells of which correspond to the cells of the transitional frequency matrix) for each of the following: transitional frequencies with row and column totals, expected frequencies, transitional probabilities, adjusted residuals and significance levels, Yule's Q values, transformed kappas (Wampold, 1989, 1992, 1995), $z$ values for the kappas, and significance levels. Sample input and output from this program appear in Appendices A and B.

Brief descriptions of the output statistics will now be provided (more comprehensive descriptions can be found in the list of references). Transitional frequencies indicate how often particular events or transitions occurred (e.g., how often behavior A followed behavior B for the specified lag). An expected transitional frequency is the expected number of times a transition would occur under the null hypothesis of independence or no relation between the codes. At this point, what is needed are ways of indexing the degrees to which transitional frequencies deviate from chance and the degrees of association between the pairs of events. Transitional probabilities provide a step in this direction. A transitional probability is a conditional probability indicating the likelihood of, for example, behavior $B$ occurring, given that behavior $A$. occurred (the probability of $B$, given $A$ ). It is computed by dividing each cell frequency by the total row frequency.

While transitional probabilities are descriptively useful, they are affected by the base rates for the two codes involved, which makes them difficult to evaluate across individuals and groups. Therefore, the currently recommended practice is to evaluate the statistical significance of particular transitions by computing $z$ scores, which are often called adjusted residuals in this literature. These coefficients are then evaluated by reference to the standard normal distribution. Adjusted residuals can be used for tests of statistical significance, but they, too, are affected by the number of data points, which makes them a less-than-ideal index of effect size. Strength of association is, therefore, more properly represented by indices such as Yule's Q and Wampold's transformed kappa, which are computed by the SEQUENTIAL program. These two statistics are descriptively useful because their values may range from -1 to +1 , with zero indicating no 
Table 1

SPSS Commands for Generating a Transitional Frequency Matrix and Transforming It for Further Analyses

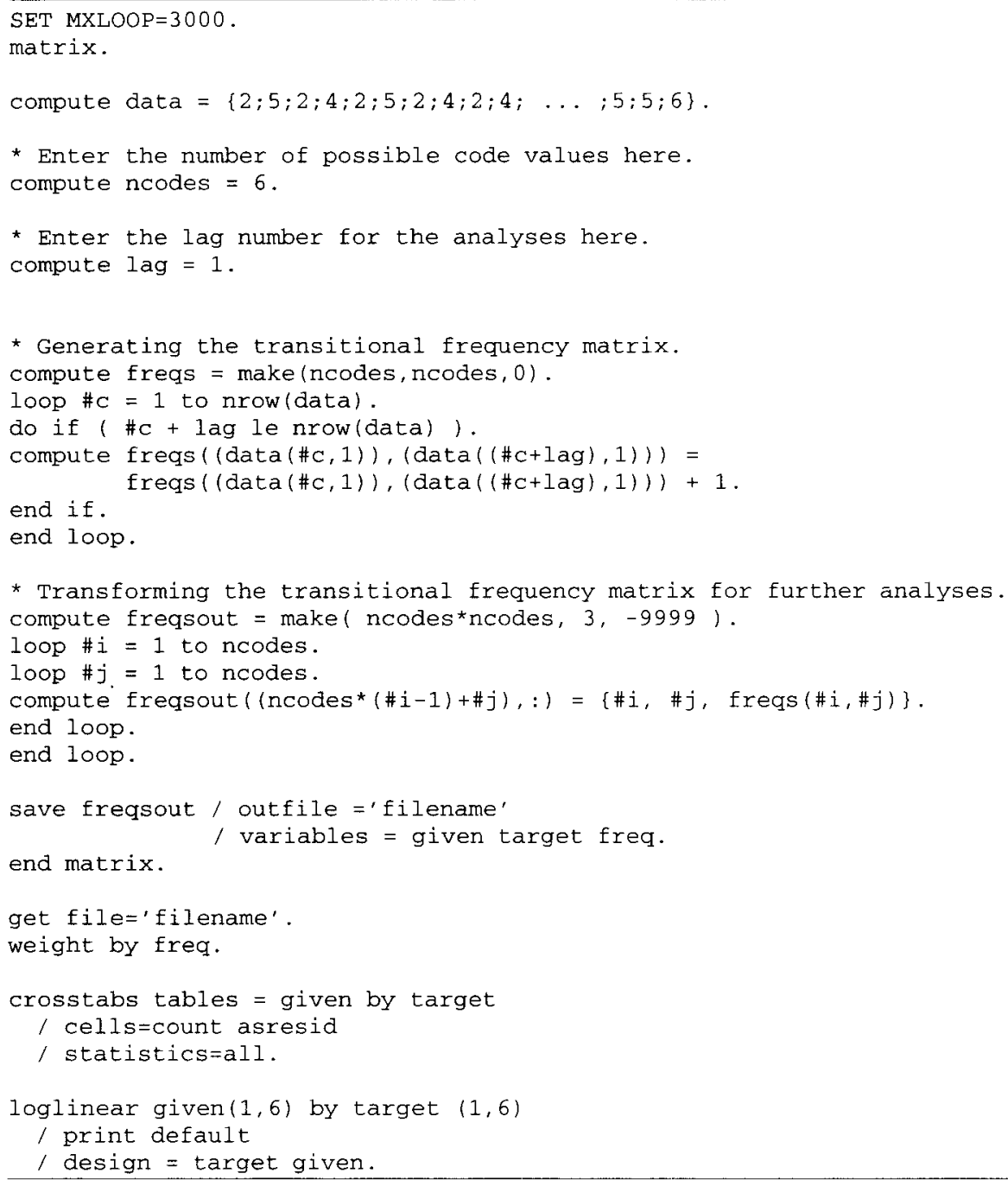

association, just like the Pearson correlation. However, it should be noted that Bakeman, McArthur, and Quera (1996) found that transformed kappa displayed less rank order invariance than did Yule's Q and a noticeably negative skew.

The SEQUENTIAL program also displays the results of an omnibus likelihood ratio chi-square test, indicating whether there is significant interdependence within the transitional frequency matrix for the specified lag. If this whole-table value is not statistically significant, the significance levels for individual cells should probably not be examined. The situation is analogous to omnibus $F$ ratios and post hoc tests for group differences in an analysis of variance (Bakeman \& Gottman, 1997, p. 118). A command at the outset of the program permits users to specify whether consecutive codes can or cannot repeat that is, whether structural zeros are possible along the main diagonal of the transitional frequency matrix. Maximum likelihood estimation of the expected cell frequencies, using iterative proportional fitting, is performed when consecutive codes cannot repeat, and the adjusted residuals are computed by using the recommended procedures (see Bakeman \& Gottman, 1997; Bakeman \& Quera, 1995b; Christensen, 1997, p. 357). Users may also specify whether one- or two-tailed significance tests are desired. Finally, the program saves whatever sequential statistics the user desires in an output file that can be read by SAS or SPSS for further processing.

SEQGROUPS. This program is the same as the above SEQUENTIAL program, except that the analyses are conducted for multiple groups/segments/cases and some additional statistics are provided. When preparing the data for analyses, the user simply inserts a number greater than 999 at the start of each sequence of codes for a given 
group or segment. The program breaks the stream of codes into the groups or the segments specified by the user in this way, and the program provides all the above statistics for each group or segment (if so desired) and all the above statistics for the data pooled across groups or segments. A further likelihood ratio chi-square test is also conducted, and its interpretation depends on whether the "groups" specified by the user were actually data from different groups/dyads/cases, or whether the "groups" were merely segments of codes from the same group/ dyad/case. A compute statement at the outset of the program permits users to specify which of these is the case (i.e., groups or segments). When the "groups" in the data are actually different groups/dyads/cases, the likelihood ratio chi-square value that is produced is a test of the homogeneity of the transitional frequency matrices across the groups. When the "groups" specified by the user are segments from a single stream of observations, the likelihood ratio chi-square value that is produced is a test of stationarity across the segments (Bakeman \& Gottman, 1997, p. 139; Gottman \& Roy, 1990). Sequential statistics for data pooled across groups or segments are not meaningful when there is a lack of homogeneity across groups or a lack of stationarity across time. When such violations occur, researchers should find alternative ways of pooling their data that do not result in such violations (Gottman \& Roy, 1990), or they should analyze their data for each group or segment separately or in relation to external covariate data (e.g., socioeconomic status, degree of marital distress).

BIDIRECTIONAL. This program tests the bidirectional dependence of behaviors $i$ to $j$ and $j$ to $i$, an additive sequential pattern described above and by Wampold and Margolin (1982) and Wampold (1989, 1992, 1995). Significant cells indicate the existence of circuits between the sequences. The program displays the transitional frequency matrix and matrices of expected and observed bidirectional frequencies, bidirectional kappas, $z$ values for the kappas, and significance levels for the kappas.

TWOCELLS. This program simultaneously tests the unidirectional dependence of $i$ to $j$ and the unidirectional dependence of $k$ to $L$, an additive pattern described by Wampold and Margolin (1982) and Wampold (1989, $1992,1995)$. The user specifies the code values to be used in the positions of $i, j, k$, and $L$ in the analyses. The program displays the transitional frequency matrix, observed and expected values for the two cell test, kappa, the $z$ value for kappa, and the significance level.

PARADOM. This program tests for parallel dominance or asymmetry in predictability, which is the difference in predictability between $i$ to $j$ and $j$ to $i$ (e.g., whether B's behavior is more predictable from A's previous behavior than vice versa), as described above and by Wampold (1984, 1989, 1992, 1995). The program displays the transitional frequency matrix and the matrices of expected frequencies, expected and observed parallel dominance frequencies, parallel dominance kappas, $z$ values for the kappas, and significance levels. There are four possible cases, or kinds, of parallel dominance (see Wampold, 1989, 1992, 1995), and the program displays a matrix indicating the kind of case for each cell in the transitional frequency matrix.

NONPARADOM. This program tests for nonparallel dominance, another form of asymmetry in predictability, between $i$ to $j$ and $k$ to $L$ (Wampold, 1984, 1989, 1992, 1995). The user specifies the code values to be used in the positions of $i, j, k$, and $L$ in the analyses. The program displays the transitional frequency matrix, expected frequencies, expected and observed nonparallel dominance frequencies, kappas, the $z$ value for kappas, and significance levels.

\section{Permutation Tests of Significance}

The statistical significance levels for the adjusted residuals and $z$ values that are printed in the above programs are based on the standard normal distribution. However, Bakeman, Robinson, and Quera (1996) recently described problems with this common practice in sequential analysis research and recommended that permutation tests of significance be used instead. Permutation tests require fewer assumptions than parametric tests and provide more exact estimates of $p$ values. A test statistic is computed; the data are then permuted many times, and the test statistic is computed for each permutation. The proportion of permuted test results that is greater than or equal to (or less than or equal to) the value for the nonpermuted data is the significance level (Edgington, 1995). Systematic permutation tests are based on the complete set of possible permutations of the data and are often not practical to compute. However, random data or sampled permutation tests, which, in the case of sequential analysis, involves randomly shuffling the sequence of codes, can be conducted in much less time. A program for this purpose was described by Bakeman, Robinson, and Quera (1996). It is written in C and requires first preparing the data, using Bakeman and Quera's SDIS program. It also does not conduct permutation tests for the sequential statistics described by Wampold and Margolin.

Commands for conducting permutation tests of significance are included in each of the programs described above (with the exception of SEQGROUPS, for which such tests are not necessary). In each program, the user specifies whether such tests are desired and, if so, the number of desired permutations per block and the number of desired blocks of permutations. The sequence of data codes is shuffled, using the algorithm recommended by Castellan (1992). The program displays mean significance levels and confidence intervals for the mean significance levels $(95 \%$ or $99 \%$, as determined by the user) on the basis of the blocks of permutations. The SAS and SPSS permutation tests of significance run slowly on personal computers, but faster on mainframes. Specifying 10 blocks of 100 permutations should provide reasonably accurate estimates of significance levels at the first two decimal places, which should be sufficient for most purposes or, at least, for trial scans of the data. Much 
faster and simple-to-use Fortran 77 versions of the above programs were written and are recommended for quickly obtaining stable estimates of significance levels with small confidence intervals based on large numbers of permutations.

\section{Input}

For all programs, the analyses are conducted on a column matrix of data, which can be created and read into the programs in a variety of ways. The SPSS "compute data" command (see Table 1) creates the data matrix within the matrix processing environment. However, raw data files can be read, using the READ command. Data matrices can also be read into the programs, using the GET command, which reads previously saved matrix data as well as SPSS system files. Alternative procedures for entering data in SAS include the USE, READ, INFILE, INPUT, and EDIT commands. In all cases, the only restriction is that the data files consist of a column of codes whose values range from " 1 " to the specified number of codes.

\section{Program Notes}

An additional file provides references and notes on some of the key computations. An SAS version of the commands in Table 1 is included. Commands for computing and printing matrices of Sackett $z$ values, GottmanAllison-Liker $z$ values, and their significance levels are provided and can easily be inserted into the SEQUENTIAL and SEQGROUPS programs. Previously, these $z$ values were often computed and discussed in the sequential analysis literature and may be preferred by some users, despite arguments by Bakeman and Gottman (1997) favoring the use of adjusted residuals instead. Commands for saving matrix output data for external use or further processing in SPSS and SAS are provided. Commands are also provided for computing transitional frequency matrices from two parallel (overlapping) streams of codes. For example, codes may be available for both husband and wife for each of a series of intervals. The user simply creates a two-column data matrix, and slight adjustments to the commands in Table 1 can be made to produce transitional frequency matrices (four in all; e.g., husband to husband, husband to wife, wife to husband, wife to wife) for the two columns of data. The programs are sufficiently simple and flexible to permit insertions of computations for any alternative sequential statistics users may desire.

\section{Sample Input and Output}

Sample input data from Gottman and Roy $(1990$, p. 78$)$ are provided in Appendix A. The output from running this data in program SEQUENTIAL appears in Appendix B. The output includes simple descriptive statistics (transitional frequencies, expected frequencies, transitional probabilities), indices of statistical significance and their associated probability levels (the omnibus likelihood ratio chi-square test, the adjusted residuals, and the $z$ values for the transformed kappas), and two indices of effect size (Yule's Q values and transformed kappas). Also included in the sample output are the results of the permutation tests of significance (mean significance levels and their confidence intervals).

\section{Comparisons With Other Programs}

A variety of other useful programs for sequential analyses are available, and they appear in a variety of programming languages (Arundale, 1984; File \& Todman, 1994; Gardner, 1990; Symons, Wright, \& Moran, 1988; Yoder \& Tapp, 1990). Apparently, the only existing software for computing transformed kappa in tests of unidirectional and bidirectional dependence and parallel and nonparallel dominance is Wampold, Roll, and East's (1989) Sequential Analysis Program. Recent programs by Bakeman and Quera (1995a) permit analyses of occurrences, nonoccurrences, and their durations (unlike the present program, which does not process duration data). However, the Bakeman and Quera programs do not provide tests for parallel and nonparallel dominance or tests for bidirectional relationships. The present programs provide such tests; they are written in familiar software languages; and they do not require the purchase of additional books and software.

\section{Availability}

The programs may be downloaded from the following internet address: http://flash.Lakeheadu.ca/ boconno2/ sequential.html. The programs may also be obtained by email from the author at brian.oconnor@lakeheadu.ca or by sending a stamped, self-addressed disk mailer to the author.

\section{REFERENCES}

ARUndale, R. B. (1984). SAMPLE and TEST: Two FORTRAN IV programs for analysis of discrete-state, time-varying data using firstorder, Markov-chain techniques. Behavior Research Methods, Instruments, \& Computers, 16, 335-336.

Bakeman, R., Adamson, L. B., \& Strisik, P. (1995). Lags and logs: Statistical approaches to interaction. In J. M. Gottman (Ed.), The analysis of change (pp. 261-276). Mahwah, NJ: Erlbaum.

Bakeman, R., \& GotTman, J. M. (1997). Observing interaction: An introduction to sequential analysis. New York: Cambridge University Press.

Bakeman, R., McARThur, D., \& Quera, V. (1996). Detecting group differences in sequential association using sampled permutations: Log odds. kappa, and phi compared. Behavior Research Methods, Instruments, \& Computers, 28, 446-457.

BaKeman, R., \& Quera, V.(1995a). Analyzing interaction: Sequential analysis with SDIS and GSEQ. New York: Cambridge University Press.

Bakeman, R., \& Quera, V. (1995b). Log-linear approaches to lagsequential analysis when consecutive codes may and cannot repeat. Psychological Bulletin, 118, 272-284.

Bakeman, R., Robinson, B. F., \& Quera, V. (1996). Testing sequential association: Estimating exact $p$ values using sampled permutations. Psychological Methods, 1, 4-15. 
Castellan, N. J., JR. (1992). Shuffling arrays: Appearances may be deceiving. Behavior Research Methods, Instrumentation, \& Computers, 24, 72-77.

CHRISTENSEN, R. (1997). Log-linear models and logistic regression. New York: Springer-Verlag.

Cordova, J. V., Jacobson, N. S., Gottman, J. M., Rushe, R., \& Cox, G. (1993). Negative reciprocity and communication in couples with a violent husband. Journal of Abnormal Psychology, 102, 559-564.

Coyne, J. C., Burchill, S. A. L., \& Stiles, W. B. (1991). An interactional perspective on depression. In C. R. Snyder \& D. R. Forsyth (Eds.), Handbook of social and clinical psychology. New York: Pergamon.

Edgington, E. S. (1995). Randomization tests. New York: Marcel Dekker.

FiLe, P. E., \& TODMan, J. (1994). Identification of sequential dependencies in conversations: A Pascal program. Behavior Research Methods, Instruments, \& Computers, 26, 65-69.

GARDNER, W. (1990). CONTIME: Continuous-time analysis of parallel streams of behavior. Multivariate Behavioral Research, 25, 205-206.

GotTMan, J. M., \& RoY, A. K. (1990). Sequential analysis: A guide for behavioral researchers. New York: Cambridge University Press.

Holloway, E. L., Freund, R. D., Gardner, S. L., Nelson, M. L., \& WALKER, B. R. (1989). Relation of power and involvement to theoretical orientation in supervision: An analysis of discourse. Journal of Counseling Psychology, 36, 88-102.

Holloway, E. L., Wampold, B. E., \& Nelson, M. L. (1990). Use of paradoxical intervention with a couple: An interactional analysis. Journal of Family Psychology, 3, 385-402.

KIESLER, D. J. (1996). Contemporary interpersonal theory and research: Personality, psychopathology, and psychotherapy. New York: Wiley.
Margolin, G., \& Wampold, B. E. (1981). Sequential analysis of conflict and accord in distressed and nondistressed marital partners. Journal of Consulting and Clinical Psychology, 49, 554-567.

RoLOFF, M. E., \& MilLER, G. R. (EDS.). (1987). Interpersonal processes: New directions in communications research. Newbury Park, CA: Sage.

Symons, D. K., Wright, R. D., \& Moran, G. (1988). Computing lag sequential statistics on dyadic time interval data: The TLAG program. Behavior Research Methods, Instruments, \& Computers, 20, 343-346.

WAMPOLD, B. E. (1984). Tests of dominance in sequential categorical data. Psychological Bulletin, 96, 424-429.

WAMPOLD, B. E. (1989). Kappa as a measure of pattern in sequential data. Quality \& Quantity, 23, 171-187.

WAMPOLD, B. E. (1992). The intensive examination of social interactions. In T. Kratochwill \& J. Levin (Eds.), Single-case research design and analysis: New directions for psychology and education (pp. 93-131). Hillsdale, NJ: Erlbaum.

WAMPOLD, B. E. (1995). Analysis of behavior sequences in psychotherapy. In J. Siegfried (Ed.), Therapeutic and everyday discourse as behavior change: Towards a micro-analysis in psychotherapy process research (pp. 189-214). Norwood, NJ: Ablex.

WAMPOLD, B. E., \& KIM, K. H. (1989). Sequential analysis applied to counseling process and outcome: A case study revisited. Journal of Counseling Psychology, 36, 357-364.

WAMPOLD, B. E., \& MARGOLIN, G. (1982). Nonparametric strategies to test the independence of behavioral states in sequential data. Psychological Bulletin, 92, 755-765.

WAMPOLD, B. E., RoLl, R., \& EAST, T. (1989), Sequential analysis program (SAP) [Computer program]. Salt Lake City: University of Utah.

YODER, P. J., \& TAPP, J. T., SR. (1990). SATS: Sequential analysis of transcripts system. Behavior Research Methods, Instruments, \& Computers, 22, 339-343.

$\begin{gathered}\text { APPENDIX A } \\ \text { Sample Input Data (SPSS) }\end{gathered}$
Compute coup $145=\{$
$2 ; 5 ; 2 ; 4 ; 2 ; 5 ; 2 ; 4 ; 2 ; 4 ; 2 ; 2 ; 5 ; 2 ; 4 ; 2 ; 5 ; 3 ; 4 ; 3 ; 4 ; 1 ; 4 ; 4 ; 1 ; 2 ; 5 ; 2 ; 1 ; 5 ; 4 ; 2 ; 5 ;$
$1 ; 4 ; 4 ; 2 ; 3 ; 6 ; 6 ; 2 ; 2 ; 6 ; 5 ; 5 ; 5 ; 6 ; 3 ; 6 ; 3 ; 3 ; 6 ; 3 ; 2 ; 5 ; 3 ; 5 ; 2 ; 6 ; 2 ; 2 ; 2 ; 5 ; 2 ; 4 ; 4 ;$
$5 ; 2 ; 5 ; 2 ; 5 ; 5 ; 4 ; 2 ; 5 ; 5 ; 5 ; 2 ; 5 ; 2 ; 5 ; 2 ; 5 ; 2 ; 2 ; 5 ; 2 ; 5 ; 2 ; 2 ; 5 ; 5 ; 2 ; 2 ; 2 ; 5 ; 2 ; 5 ; 2 ;$
$5 ; 2 ; 5 ; 2 ; 2 ; 5 ; 2 ; 5 ; 3 ; 5 ; 2 ; 5 ; 5 ; 2 ; 2 ; 5 ; 2 ; 2 ; 5 ; 2 ; 6 ; 2 ; 5 ; 4 ; 2 ; 5 ; 2 ; 4 ; 4 ; 2 ; 1 ; 2 ; 5 ;$
$2 ; 5 ; 2 ; 5 ; 5 ; 5 ; 3 ; 5 ; 2 ; 5 ; 5 ; 2 ; 5 ; 5 ; 2 ; 5 ; 2 ; 5 ; 2 ; 4 ; 2 ; 4 ; 2 ; 5 ; 4 ; 2 ; 2 ; 5 ; 2 ; 5 ; 5 ; 5 ; 2 ;$
$5 ; 2 ; 5 ; 5 ; 2 ; 5 ; 2 ; 5 ; 5 ; 2 ; 1 ; 2 ; 5 ; 1 ; 5 ; 1 ; 5 ; 5 ; 4 ; 2 ; 2 ; 2 ; 3 ; 6 ; 3 ; 6 ; 3 ; 6 ; 3 ; 6 ; 3 ; 6 ; 3 ;$
$3 ; 6 ; 6 ; 6 ; 5 ; 1 ; 2 ; 5 ; 2 ; 5 ; 5 ; 2 ; 4 ; 5 ; 5 ; 2 ; 5 ; 5 ; 2 ; 5 ; 2 ; 5 ; 2 ; 5 ; 1 ; 5 ; 4 ; 2 ; 2 ; 5 ; 2 ; 5 ; 2$
$5 ; 4 ; 1 ; 4 ; 4 ; 2 ; 4 ; 4 ; 2 ; 4 ; 2 ; 3 ; 5 ; 4 ; 2 ; 2 ; 5 ; 2 ; 6 ; 1 ; 4 ; 1 ; 4 ; 5 ; 5 ; 5 ; 4 ; 5 ; 2 ; 4 ; 5 ; 5 ; 2$
$5 ; 2 ; 2 ; 2 ; 5 ; 2 ; 2 ; 5 ; 2 ; 2 ; 4 ; 2 ; 2 ; 2 ; 6 ; 2 ; 4 ; 3 ; 3 ; 3 ; 3 ; 2 ; 3 ; 6 ; 3 ; 5 ; 3 ; 3 ; 5 ; 3 ; 2 ; 2 ; 2$
$2 ; 6 ; 3 ; 6 ; 3 ; 6 ; 2 ; 6 ; 1 ; 6 ; 3 ; 3 ; 3 ; 3 ; 5 ; 3 ; 5 ; 2 ; 5 ; 3 ; 3 ; 6 ; 3 ; 1 ; 4 ; 1 ; 5 ; 1 ; 5 ; 6 ; 3 ; 3 ; 6$
$3 ; 6 ; 3 ; 6 ; 3 ; 6 ; 3 ; 6 ; 3 ; 3 ; 6 ; 3 ; 6 ; 3 ; 2 ; 5 ; 2 ; 5 ; 2 ; 5 ; 2 ; 5 ; 2 ; 2 ; 2 ; 3 ; 5 ; 1 ; 6 ; 1 ; 6 ; 6 ; 6 ;$
$1 ; 6 ; 6 ; 1 ; 6 ; 1 ; 6 ; 2 ; 5 ; 1 ; 6 ; 6 ; 6 ; 2 ; 2 ; 6 ; 6 ; 6 ; 2 ; 6 ; 2 ; 6 ; 2 ; 5 ; 5 ; 5 ; 5 ; 5 ; 5 ; 6\}$

Note-The sample data are from Gottman and Roy $(1990$, p. 78 ). 


\section{Sample Output Data from Program SEQUENTIAL (SPSS)}

Run MATRIX procedure:

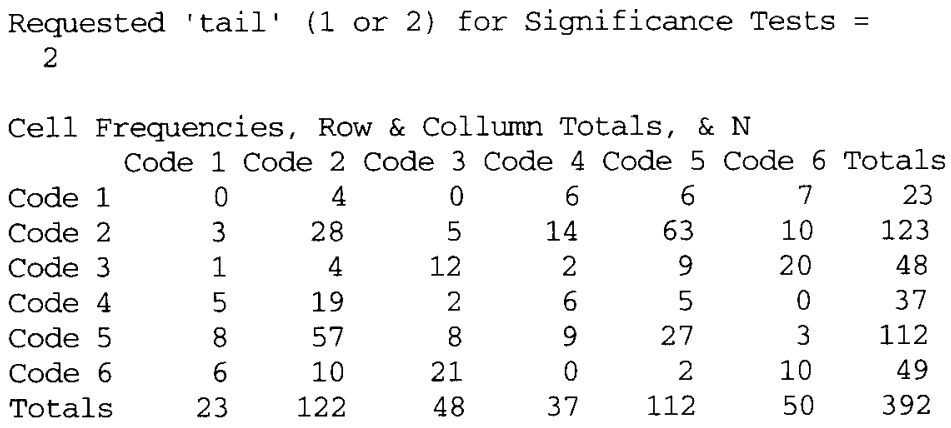

Expected Values/Frequencies

Code 1 code 2 Code 3 code 4 code 5 code 6

$\begin{array}{lllllllll}\text { Code } 1 & 1.3495 & 7.1582 & 2.8163 & 2.1709 & 6.5714 & 2.9337\end{array}$

$\begin{array}{llllllll}\text { Code } 2 & 7.2168 & 38.281 & 15.061 & 11.610 & 35.143 & 15.689\end{array}$

$\begin{array}{llllllll}\text { Code } 3 & 2.8163 & 14.939 & 5.8776 & 4.5306 & 13.714 & 6.1224\end{array}$

Code $4 \quad 2.1709 \quad 11.515 \quad 4.5306 \quad 3.4923 \quad 10.571 \quad 4.7194$

Code $5 \quad 6.5714 \quad 34.857 \quad 13.714 \quad 10.571 \quad 32.000 \quad 14.286$

Code $6 \quad 2.8750 \quad 15.250 \quad 6.0000 \quad 4.6250 \quad 14.0006 .2500$

Transitional Probabilities

Code 1 Code 2 code 3 code 4 code 5 code 6

$\begin{array}{lllllll}\text { Code } 1 & .0000 & .1739 & .0000 & .2609 & .2609 & .3043\end{array}$

$\begin{array}{lllllll}\text { Code } 2 & .0244 & .2276 & .0407 & .1138 & .5122 & .0813\end{array}$

$\begin{array}{lllllll}\text { Code } 3 & .0208 & .0833 & .2500 & .0417 & .1875 & .4167\end{array}$

$\begin{array}{lllllll}\text { Code } 4 & .1351 & .5135 & .0541 & .1622 & .1351 & .0000\end{array}$

$\begin{array}{lllllll}\text { Code } 5 & .0714 & .5089 & .0714 & .0804 & .2411 & .0268\end{array}$

$\begin{array}{llllllll}\text { Code } 6 & .1224 & .2041 & .4286 & .0000 & .0408 & .2041\end{array}$

Tablewise Likelihood Ratio (Chi-Square) Test

LRX2 df sig.

$202.5009 \quad 25.0000 \quad .0000$

Adjusted Residuals

Code 1 Code 2 Code 3 Code 4 Code 5 Code 6

$\begin{array}{lllllll}\text { code } 1 & -1.234 & -1.466 & -1.846 & 2.815 & -.272 & 2.620\end{array}$

$\begin{array}{lllllll}\text { Code } 2 & -1.953 & -2.417 & -3.341 & .890 & 6.712 & -1.856\end{array}$

$\begin{array}{lllllll}\text { Code } 3 & -1.191 & -3.640 & 2.878 & -1.334 & -1.608 & 6.410\end{array}$

$\begin{array}{lllllll}\text { Code } 4 & 2.080 & 2.793 & -1.334 & 1.482 & -2.131 & -2.444\end{array}$

$\begin{array}{llllllll}\text { Code } 5 & .680 & 5.347 & -1.949 & -.601 & -1.237 & -3.782\end{array}$

$\begin{array}{lllllll}\text { Code } 6 & 2.031 & -1.732 & 6.988 & -2.416 & -4.057 & 1.717\end{array}$

Significance Levels for the Adjusted Residuals Code 1 Code 2 Code 3 code 4 Code 5 code 6

$\begin{array}{lllllll}\text { Code } 1 & .2172 & .1427 & .0648 & .0049 & .7857 & .0088\end{array}$

$\begin{array}{lllllll}\text { Code } 2 & .0508 & .0157 & .0008 & .3735 & .0000 & .0634\end{array}$

$\begin{array}{lllllll}\text { Code } 3 & .2337 & .0003 & .0040 & .1823 & .1079 & .0000\end{array}$

$\begin{array}{lllllll}\text { Code } 4 & .0376 & .0052 & .1823 & .1384 & .0331 & .0145\end{array}$

$\begin{array}{lllllll}\text { Code } 5 & .4967 & .0000 & .0513 & .5479 & .2159 & .0002\end{array}$

$\begin{array}{lllllll}\text { Code } 6 & .0423 & .0833 & .0000 & .0157 & .0000 & .0860\end{array}$ 


\section{APPENDIX B (Continued)}

\begin{tabular}{lrrrrrr}
\hline Yule's Q Values & \multicolumn{1}{c}{ Code 1 Code 2} & Code 3 & Code 4 & Code 5 & Code 6 \\
Code 1 & -1.000 & -.381 & -1.000 & .587 & -.066 & .537 \\
Code 2 & -.525 & -.291 & -.636 & .157 & .650 & -.327 \\
Code 3 & -.525 & -.703 & .481 & -.445 & -.299 & .764 \\
Code 4 & .490 & .442 & -.445 & .338 & -.468 & -1.000 \\
Code 5 & .152 & .548 & -.368 & -.120 & -.157 & -.760 \\
Code 6 & .456 & -.308 & .795 & -1.000 & -.835 & .320
\end{tabular}

Unidirectional Kappas

Code 1 Code 2 Code 3 Code 4 Code 5 Code 6

$\begin{array}{lllllll}\text { Code } 1 & -1.000 & -.4443 & -1.000 & .1840 & -.0846 & .2029\end{array}$

$\begin{array}{lllllll}\text { Code } 2 & -.5832 & -.2727 & -.6672 & .0952 & .3632 & -.3610\end{array}$

$\begin{array}{lllllll}\text { Code } 3 & -.6440 & -.7337 & .1457 & -.5574 & -.3421 & .3316\end{array}$

$\begin{array}{llllllll}\text { Code } 4 & .1361 & .2919 & -.5574 & .0751 & -.5258 & -1.000\end{array}$

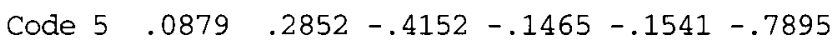

$\begin{array}{lllllll}\text { Code } 6 & .1531 & -.3610 & .3555 & -1.000 & -.8596 & .0834\end{array}$

$z$ Values for the Unidirectional Kappas

Code 1 Code 2 Code 3 Code 4 Code 5 Code 6

$\begin{array}{lllllll}\text { Code } 1 & -1.231 & -1.480 & -1.841 & 2.818 & -.264 & 2.624\end{array}$

$\begin{array}{lllllll}\text { Code } 2 & -1.943 & -2.459 & -3.326 & .900 & 6.726 & -1.842\end{array}$

$\begin{array}{lllllll}\text { Code } 3 & -1.186 & -3.657 & 2.884 & -1.327 & -1.595 & 6.415\end{array}$

$\begin{array}{llllllll}\text { Code } 4 & 2.083 & 2.760 & -1.327 & 1.487 & -2.119 & -2.437\end{array}$

$\begin{array}{lllllll}\text { Code } 5 & .687 & 5.282 & -1.936 & -.590 & -1.216 & -3.768\end{array}$

$\begin{array}{lllllll}\text { Code } 6 & 1.980 & -1.842 & 6.876 & -2.437 & -4.103 & 1.651\end{array}$

Significance Levels for the Unidirectional Kappas Code 1 Code 2 Code 3 Code 4 Code 5 Code 6

$\begin{array}{lllllll}\text { Code } 1 & .2184 & .1388 & .0656 & .0048 & .7920 & .0087 \\ \text { Code } 2 & .0520 & .0139 & .0009 & .3680 & .0000 & .0655 \\ \text { Code } 3 & .2357 & .0003 & .0039 & .1845 & .1107 & .0000 \\ \text { Code } 4 & .0372 & .0058 & .1845 & .1371 & .0341 & .0148 \\ \text { Code } 5 & .4920 & .0000 & .0529 & .5550 & .2240 & .0002 \\ \text { Code } 6 & .0477 & .0655 & .0000 & .0148 & .0000 & .0988\end{array}$

Permutation Tests of Significance:

Number of permutations per block: 1000

Number of blocks of permutations: 10

Mean Significance Levels Code 1 Code 2 code 3 Code 4 Code 5 Code 6 $\begin{array}{lllllll}\text { Code } 1 & .37890 & .16610 & .09050 & .01400 & .81660 & .01410\end{array}$

$\begin{array}{lllllll}\text { Code } 2 & .05970 & .01850 & .00060 & .46340 & .00000 & .07570\end{array}$

$\begin{array}{lllllll}\text { Code } 3 & .33300 & .00090 & .00580 & .20660 & .12750 & .00000\end{array}$

$\begin{array}{lllllll}\text { Code } 4 & .05570 & .00790 & .20750 & .13100 & .03490 & .01670\end{array}$

$\begin{array}{lllllll}\text { Code } 5 & .63200 & .00000 & .06550 & .57750 & .26500 & .00010\end{array}$

$\begin{array}{llllllll}\text { Code } 6 & .05810 & .10330 & .00000 & .01360 & .00020 & .10380\end{array}$

Percentage for the Confidence Intervals: 95 
APPENDIX B (Continued)

\begin{tabular}{|c|c|c|c|c|c|c|}
\hline & Code 1 & Code 2 & Code 3 & Code 4 & Code 5 & Code 6 \\
\hline Code & .38868 & .17553 & .09550 & .01644 & .82396 & .01566 \\
\hline Code & .06533 & .02028 & .00112 & .47211 & .00000 & .08132 \\
\hline Code & .34134 & .00144 & .00747 & .21125 & .13420 & .00000 \\
\hline Code & .05923 & .00989 & .21426 & .13874 & .03992 & .01843 \\
\hline Code & .64930 & .00000 & .07108 & .58828 & .27164 & .00030 \\
\hline de & $\begin{array}{ll}6 & .06310\end{array}$ & .10766 & .00000 & .01585 & .00046 & .11023 \\
\hline \multicolumn{7}{|c|}{ Low Ends of the Co } \\
\hline & Code 1 & Code 2 & Code 3 & Code 4 & Code 5 & Code 6 \\
\hline Code & .36912 & .15667 & .08550 & .01156 & .80924 & .01254 \\
\hline Code & 2.05407 & .01672 & .00008 & .45469 & .00000 & .07008 \\
\hline Code & .32466 & .00036 & .00413 & .20195 & .12080 & .00000 \\
\hline Code & .05217 & . 00591 & .20074 & .12326 & .02988 & .01497 \\
\hline Code & $5 \quad .61470$ & .00000 & .05992 & .56672 & .25836 & -.00010 \\
\hline Code & .05310 & .09894 & .00000 & .01135 & -.00006 & .09737 \\
\hline
\end{tabular}

(Manuscript received October 5, 1998; revision accepted for publication April 2, 1999.) 